\title{
Does prophylactic sotalol and magnesium decrease the incidence of atrial fibrillation following coronary artery bypass surgery: a propensity-matched analysis
}

\author{
V Aerra ${ }^{1}$, M Kuduvalli1 ${ }^{1}$, AN Moloto ${ }^{1}$, AK Srinivasan ${ }^{1}$, AD Grayson*2,3, \\ BM Fabri ${ }^{1}$ and AY Oo ${ }^{1}$
}

\author{
Address: ${ }^{1}$ Department of Cardiothoracic Surgery. The Cardiothoracic Centre Liverpool, UK, ${ }^{2}$ Department of Research and Development. The \\ Cardiothoracic Centre Liverpool, UK and ${ }^{3}$ Senior Clinical Information Analyst, Clinical Governance Department. The Cardiothoracic Centre- \\ Liverpool, Thomas Drive, Liverpool, L14 3PE, UK \\ Email:V Aerra - vikram.aerra@gmail.com; M Kuduvalli - Manoj.Kuduvalli@ctc.nhs.uk; AN Moloto - adelard2004@yahoo.fr; \\ AK Srinivasan - arunsri0@ hotmail.com; AD Grayson* - Tony.Grayson@ctc.nhs.uk; BM Fabri - Brian.Fabri@ctc.nhs.uk; \\ AY Oo - Aung.Oo@ctc.nhs.uk \\ * Corresponding author
}

Published: 03 March 2006

Journal of Cardiothoracic Surgery2006, I:6 doi:10.1186/1749-8090-1-6

This article is available from: http://www.cardiothoracicsurgery.org/content/I/I/6

(c) 2006Aerra et al; licensee BioMed Central Ltd.

This is an Open Access article distributed under the terms of the Creative Commons Attribution License (http://creativecommons.org/licenses/by/2.0), which permits unrestricted use, distribution, and reproduction in any medium, provided the original work is properly cited.
Received: 23 January 2006

Accepted: 03 March 2006

\begin{abstract}
Background: Atrial fibrillation can occur in up to $40 \%$ of patients undergoing coronary surgery.

Methods: We retrospectively analysed 103 consecutive coronary surgery patients under the care of one surgeon between April 2003 and September 2003. These patients received $40 \mathrm{mg}$ of sotalol orally twice daily from the first post-operative day for 6 weeks and $2 \mathrm{~g}$ of magnesium intravenously immediately post surgery and on the first post-operative day. We developed a propensity score for the probability of receiving sotalol and magnesium after coronary surgery. 89 patients from the sotalol and magnesium group were successfully matched with 89 unique coronary surgery patients who did not receive either sotalol or magnesium with an identical propensity score.
\end{abstract}

Results: Preoperative characteristics were well matched between groups. There was no significant difference with respect to in-hospital mortality between groups (sotalol and magnesium I.1\% versus control $4.5 \% ; p=0.17$ ). The incidence of atrial fibrillation in the sotalol and magnesium group was $13.5 \%$ compared to $27.0 \%$ in the controls $(p=0.025)$.

Conclusion: The combination of sotalol and magnesium can significantly reduce the incidence of post-operative atrial fibrillation following coronary surgery.

\section{Introduction}

Atrial Fibrillation is the most common complication following cardiac surgery with a reported incidence between $20 \%$ and $40 \%[1,2]$. It usually occurs between the second and fourth post-operative day. However, although this complication occurs frequently, the mechanism behind its development is less understood.
Numerous studies have identified and enumerated a variety of risk factors for the development of atrial fibrillation. These include increased age, male gender, history of atrial fibrillation, discontinuation of preoperative ßeta-blocker therapy, congestive heart failure, electrolyte depletion (low potassium and magnesium), cardiopulmonary bypass, left atrial dysfunction, severity of coronary artery 
disease, respiratory disease, and pulmonary vein venting [1-7].

In an effort to prevent the occurrence of atrial fibrillation in the post-operative period, various treatment modalities have been implemented indicating its unclear pathophysiology. The key role of ßeta blockers in prevention of atrial fibrillation is well recognised in many randomised control trials $[8,9]$. Sotalol has an acceptable safety profile and is emerging as a key drug in the prevention of this complication $[9,10]$. The role of magnesium supplements is less clear [11-17].

The present study was done to examine the beneficial role of sotalol and magnesium prophylaxis in the prevention of atrial fibrillation in routine coronary artery bypass graft (CABG) surgery.

\section{Materials and methods Patient population}

Between $1^{\text {st }}$ April 2003 and 30th September 2003, 103 consecutive patients undergoing first time isolated CABG surgery under the care of one surgeon (AYO) were routinely administered sotalol and magnesium (see sotalol and magnesium). These patients were matched to a control group taken from the remaining 487 consecutive patients who received first time isolated CABG surgery performed during the same time period by other surgeons at our institution (see statistical methods).

\section{Exclusions}

Patients undergoing CABG that was in addition to heart valve repair or replacement, resection of a ventricular aneurysm or other surgical procedure were not included. Also excluded were patients who had received previous cardiac surgery or patients with a history of atrial arrhythmias.

\section{Data collection}

Definitions and data collection methods are available from http://www.nwheartaudit.nhs.uk. Data was collected prospectively during the patient's admission as part of routine clinical practice and entered into our cardiac surgery registry on the variables listed in Table 1. Postoperative atrial fibrillation, in-hospital mortality, and length of hospital stay were also documented.

\section{Sotalol and Magnesium}

Patients received $40 \mathrm{mg}$ of sotalol orally twice daily from the first post-operative day for 6 weeks and $2 \mathrm{~g}$ of magnesium intravenously immediately post-coronary surgery

Table I: Propensity-matched patient and disease characteristics

\begin{tabular}{|c|c|c|c|}
\hline & $S M(n=89)$ & Control $(n=89)$ & $P$ Value \\
\hline Age (years) & $65.9(59.2-70.1)$ & $66.4(59.2-71.9)$ & 0.58 \\
\hline Female (\%) & 28.1 & 25.8 & 0.74 \\
\hline Body mass index $(\mathrm{kg} / \mathrm{m} 2)$ & $27.1(24.9-30.7)$ & $27.1(24.7-30.2)$ & 0.81 \\
\hline Ejection fraction $<30 \%$ & 5.6 & 4.5 & 0.73 \\
\hline Triple-vessel disease (\%) & 75.3 & 74.2 & 0.86 \\
\hline Left main stem disease (\%) & 23.6 & 24.7 & 0.86 \\
\hline Angina class IV (\%) & 19.1 & 14.6 & 0.42 \\
\hline Diabetes (\%) & 23.6 & 29.2 & 0.39 \\
\hline Respiratory disease (\%) & 37.1 & 33.7 & 0.64 \\
\hline Renal dysfunction (\%) & 6.7 & 5.6 & 0.76 \\
\hline Peripheral vascular disease (\%) & 9.0 & 7.9 & 0.79 \\
\hline Current smoker (\%) & 20.2 & 20.2 & $>0.99$ \\
\hline Previous myocardial infarction (\%) & 46.1 & 51.7 & 0.45 \\
\hline Hypercholesterolaemia (\%) & 95.5 & 95.5 & $>0.99$ \\
\hline Hypertension (\%) & 57.3 & 55.1 & 0.76 \\
\hline Emergent procedure (\%) & 1.1 & 1.1 & $>0.99$ \\
\hline Preoperative $\beta$-blockers (\%) & 66.3 & 64.0 & 0.75 \\
\hline Preoperative diuretics (\%) & 33.7 & 36.0 & 075 \\
\hline Preoperative heart rate (bpm) & $69.1(61.8-81.9)$ & $70.3(60.6-83.2)$ & 0.57 \\
\hline Additive EuroSCORE & $4(2-5)$ & $3(2-5)$ & 0.63 \\
\hline Number of grafts (n/patient) & $3(2-4)$ & $3(3-4)$ & 0.61 \\
\hline Right-CAD (\%) & 76.4 & 71.9 & 0.49 \\
\hline LIMA (\%) & 95.5 & 96.6 & 0.69 \\
\hline CPB not used (\%) & 77.5 & 69.7 & 0.23 \\
\hline
\end{tabular}

SM, Sotalol and Magnesium; CPB, Cardiopulmonary Bypass; EuroSCORE, European System for Cardiac Operative Risk Evaluation; CAD, Coronary Artery Disease; LIMA, Left Internal Mammary Artery. Categorical variables are shown as a percentage. Continuous variables are shown as a median with 25 th and 75 th percentiles. 


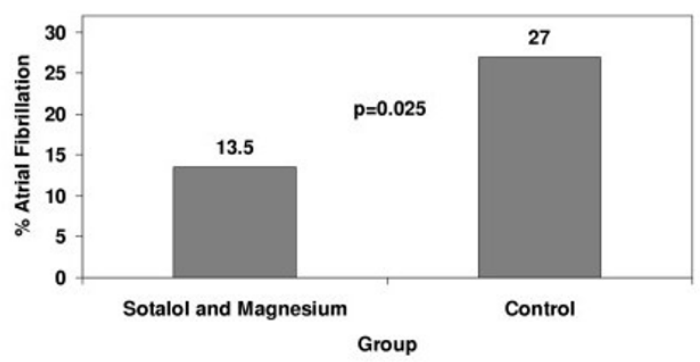

Figure I

Propensity-matched incidence of atrial fibrillation.

and on the first post-operative day. No patients from the control group received sotalol and/or magnesium.

\section{Outcome definitions}

Post-operative atrial fibrillation was defined as the occurrence of new atrial fibrillation in the absence of pre-operative persistent or paroxysmal atrial fibrillation prior to hospital discharge. In-hospital mortality was defined as death within the same hospital admission regardless of cause.

\section{Statistical methods}

In order to assess the effect of sotalol and magnesium, we performed a propensity-matched cohort analysis [18]. To do this, logistic regression was used to develop a propensity score for sotalol and magnesium group membership. The propensity score included the following variables: age, sex, body mass index, respiratory disease, renal dysfunction, peripheral vascular disease, diabetes, severity of angina and dysponea, hypertension, hypercholesterolaemia, smoking status, extent of disease, ejection fraction, priority and use of cardiopulmonary bypass. The $\mathrm{C}$ statistic, which is equivalent to the receiver-operating characteristic curve, for the propensity model was 0.85 . Sotalol and magnesium patients were matched with control patients who had an identical 5-digit propensity score. If this could not be done, we then proceeded to a 4-, 3-, 2-, or 1-digit match [19].

Continuous variables are shown as median with $25^{\text {th }}$ and $75^{\text {th }}$ percentiles and comparisons were made with Wilcoxon rank-sum tests. Categorical variables are shown as a percentage and comparisons were made with Chi-square tests. A forward stepwise logistic regression analysis was performed to identify risk factors for atrial fibrillation, which was adjusted for the propensity score. In all cases a $\mathrm{P}$ value $<0.05$ was considered significant. All statistical analysis was performed retrospectively with SAS for Windows Version 8.2 (SAS Institute, Cary, NC).

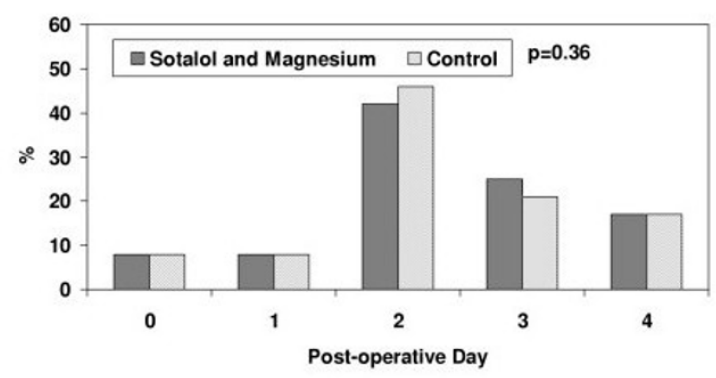

Figure 2

Time of occurrence of post-operative atrial fibrillation in propensity-matched patients.

\section{Results}

Of the 590 patients who underwent first time isolated CABG at our institution during the study period, $28.0 \%$ developed post-operative atrial fibrillation. Of the 103 patients who received sotalol and magnesium, 13.6\% developed atrial fibrillation compared to $31.0 \%$ in the other patients $(\mathrm{p}<0.001)$.

We were able to successfully match 89 patients who received sotalol and magnesium to unique control patients who did not. Of these, 5 (5.6\%) were 5-digit matches, $11(12.4 \%)$ were 4-digit matches, 40 (44.9\%) were 3-digit matches, 24 (27.0\%) were 2-digit matches, and $9(10.1 \%)$ were a 1 -digit match. The patient and disease characteristics of the propensity-matched patients are shown in Table 1.

There was no significant difference with respect to in-hospital mortality between groups (sotalol and magnesium $1.1 \%$ versus control $4.5 \% ; \mathrm{p}=0.17$ ). The median length of hospital stay in the sotalol and magnesium group and control group were both 7 days $\left[\left(25^{\text {th }}\right.\right.$ and $75^{\text {th }}$ percentiles: 6 to 9$) ; \mathrm{p}=0.38$.

The incidence of atrial fibrillation in the sotalol and magnesium group was significantly lower compared to the control group (Figure 1; $\mathrm{p}=0.025$ ); with an odds ratio of 0.42 (95\% confidence interval: 0.19 to 0.91 ). The time of occurrence of atrial fibrillation was similar between the propensity-matched patients (Figure 2; $\mathrm{p}=0.36$ ).

A logistic regression analysis confirmed the beneficial effect of sotalol and magnesium for reducing post-operative atrial fibrillation (Table 2).

\section{Comment}

Numerous studies have identified and enumerated a variety of pre-, intra- and post-operative risk factors [1-7], with the aim of being able to change practice and reduce 
Table 2: Independent risk factors for post-operative atrial fibrillation

\begin{tabular}{llll}
\hline & Odds Ratio $\dagger$ & $95 \%$ Confidence Interval & $p$ Value \\
\hline Female & 0.17 & $0.05-0.61$ & 0.006 \\
SM group & 0.39 & $0.18-0.89$ & 0.025 \\
Body mass index \# & 0.89 & $0.81-0.99$ & 0.025 \\
\hline
\end{tabular}

SM, Sotalol and Magnesium

† Adjusted for the propensity score

\# for each additional unit

the occurrence of atrial fibrillation. Several treatment modalities have been investigated and have shown the effectiveness of either prophylactic amiodarone or sotalol in reducing this complication $[9,10]$. A meta-analysis, by Wurdeman, concluded that compared to placebo, amiodarone and sotalol were both effective in reducing postoperative atrial fibrillation when used prohpylactically, and that both were equally as effective as each other [9]. Sotalol has non-selective beta-blocking as well as class III antiarrhythmic activity. In addition, it has no interaction with the other beta blockers and so patients on pre-operative beta blockers other than Sotalol could be easily switched to Sotalol for atrial fibrillation prophylaxis. Sotalol is associated with an increase in QTc interval but reported incidence of torsades de pointes is very low. It can sometimes induce profound bradycardia and hypotension and should be avoided in low cardiac output states.

Recently, Forlani and associates [20] found that the incidence of atrial fibrillation after coronary operations was significantly reduced by the administration of combination sotalol and magnesium therapy. They showed in a randomised control trial of 207 consecutive CABG patients, that administration of sotalol alone and magnesium alone significantly reduced the incidence of atrial fibrillation, but more importantly, that when combined together, the incidence of atrial fibrillation was reduced to $1.9 \%$.

The presence of hypomagnesemia following cardiac surgery is well described and has been shown to result in higher atrial myocardium excitability and an increased incidence of post-operative atrial fibrillation [14]. The role of magnesium supplementation in reducing atrial fibrillation has been extensively studied with varying results.

Hazelrigg and colleagues [11] concluded that prophylactic magnesium supplementation does not significantly reduce atrial arrhythmias, and that the only benefit occurred on the first post-operative day. Sinilarly, Parikka [12] concluded that magnesium was not sufficient for decreasing the incidence of atrial fibrillation. In a recent randomised, double-blinded, placebo controlled trial,
Geertman found that magnesium in addition to sotalol, was not more effective than sotalol alone in the prevention of tachyarrhythmias after CABG. They also found that serious bradyarrhythmias were observed in the magnesium-treated group of patients [13].

However, other reports in the literature have highlighted the potential role of magnesium for reducing arrhythmias post cardiac surgery [14-17]. Toraman and colleagues [15] found that patients who received magnesium had a reported incidence of atrial fibrillation of just $2 \%$ compared to $21 \%$ in the control group. They point out that several studies that failed to show the benefit of magnesium in reducing atrial fibrillation were not well randomised with patients in the magnesium group being older and having more preoperative palpitations and arrhythmias [12]. Alghamdi [16] published a systematic review and meta-analysis in 2005 which concluded that intravenous magnesium was associated with a significant reduction in the incidence of atrial fibrillation after coronary artery bypass surgery, with a relative risk of 0.64 (95\% CI 0.47 to $0.87 ; \mathrm{p}=0.004)$. Another meta-analysis published in the same year by Miller and colleagues showed a similar result with patients receiving magnesium having an atrial fibrillation rate of $18 \%$ compared to $28 \%$ in the control group $(\mathrm{p}<0.001)[28]$.

Our own study confirms that the combination of sotalol and magnesium can significantly reduce the incidence of post-operative atrial fibrillation, with an incidence of $13.5 \%$ compared to $27 \%$ in a propensity-matched cohort. But, unlike the study by Forlani [20], which had strict exclusion criteria, this study is based on routine clinical practice.

There are some limitations which need to be considered when drawing conclusions from this report. The first is that it is an observational study and therefore could have some degree of selection bias. The retrospective nature of the study cannot account for unknown variables affecting the outcomes that are not correlated strongly with the variables used in the propensity matching. Although, propensity score adjustment is no substitute for a properly designed randomised control trial, retrospective comparisons with propensity score adjustment are more versatile 
and may be more widely applicable to routine clinical practice [18]. Perhaps one of the most important limitations is inextricable confounding caused by the sotalol and magnesium patients being performed completely by one surgeon. Even after careful application of multivariate analyses and propensity-matching, it remains difficult to distinguish between surgeon and treatment differences. However these results are highly suggestive of a role for the use of sotalol and magnesium in CABG and we are already embarking on a randomised control trial to confirm or refute the findings of this observational study.

In conclusion, the combination of sotalol and magnesium can significantly reduce the incidence of post-operative atrial fibrillation following coronary artery bypass surgery.

\section{Acknowledgements}

We would like to acknowledge the co-operation given to us by all the Consultant Cardiac Surgeons at the Cardiothoracic Centre-Liverpool.

\section{References}

I. Zaman AG, Archbold RA, Helft G, Paul EA, Curzen NP, Mills PG: Atrial fibrillation after coronary artery bypass surgery: a model for preoperative risk stratification. Circulation I 0 I(I 2): 1403-8. 2000 Mar 28

2. Aranki SF, Shaw DP, Adams DH, Rizzo RJ, Couper GS, VanderVliet M, Collins JJ Jr, Cohn LH, Burstin HR: Predictors of atrial fibrillation after coronary artery surgery. Current trends and impact on hospital resources. Circulation 94(3):390-7. 1996 Aug I

3. Mathew IP, Fontes ML, Tudor IC, Ramsay J, Duke P, Mazer CD, Barash PG, Hsu PH, Mangano DT: A multicenter risk index for atrial fibrillation after cardiac surgery. JAMA 29I(14):1720-9. 2004 Apr 14

4. Mathew JP, Parks R, Savino JS, et al.: Atrial fibrillation following coronary artery bypass graft surgery: predictors, outcomes, and resource utilization. JAMA 1996, 276:300-306.

5. Ducceschi V, D'Andrea A, Liccardo B, Alfieri A, Sarubbi B, De Feo M, Santangelo L, Cotrufo M: Perioperative clinical predictors of atrial fibrillation occurrence following coronary artery surgery. Eur J Cardiothorac Surg 1999, 16(4):435-9.

6. Srinivasan AK, Shackcloth MJ, Grayson AD, Fabri BM: Preoperative beta-blocker therapy in coronary artery bypass surgery: a propensity score analysis of outcomes. Interactive Cardiovascular and Thoracic Surgery 2003, 2:495-500.

7. Stamou SC, Dangas G, Hill PC, Pfister AJ, Dullum MK, Boyce SW, Bafi AS, Garcia JM, Corso PJ: Atrial fibrillation after beating heart surgery. Am J Cardiol 86(I):64-7. 2000 Jul I

8. Auer J, Weber T, Berent R, Puschmann R, Hartl P, Ng CK, Schwarz C, Lehner E, Strasser U, Lassnig E, Eber B: A comparision between oral antiarrhythmic drugs in the prevention of atrial fibrillation after cardiac surgery: the pilot study of prevention of postoperative atrial fibrillation (SPPAF), a randomised, placebo-controlled trial. Am Heart J 2004, 147(4):636-43.

9. Wurdeman RL, Mooss AN, Mohiuddin SM, Lenz TL: Amiodarone vs sotalol as prophylaxis against atrial fibrillation/flutter after heart surgery: a meta-analysis. Chest 2002, 12 1:1203-1210.

10. Evrard P, Gonzalez M, Jamart J, et al.: Prophylaxis of supraventricular and ventricular arrhythmias after coronary artery bypass grafting with low-dose sotalol. Ann Thorac Surg 2000, 70:15I-6.

II. Hazelrigg SR, Boley TM, Cetindag IB, et al.: The efficacy of supplemental magnesium in reducing atrial fibrillation after coronary artery bypass grafting. Ann Thorac Surg 2004, 77:824-30.

12. Parikka H, Toivonen L, Pellinen T, Verkkala K, Jarvinen A, Nieminen $M S$ : The influence of intravenous magnesium sulphate on the occurrence of atrial fibrillation after coronary artery bypass operation. Eur Heart J 1993, 14:25I-8.
13. Geertman H, van der Starre JA, Sie HT, Beukema WP, van RooyenButijn M: Magnesium in addition to sotalol does not influence the incidence of post-operative atrial tachyarrhythmias after coronary artery bypass surgery. J Cardiothorac Vasc Anesth 2004, I8:309-3|2.

14. England MR, Gordon G, Salem M, Chernow B: Magnesium administration and disrhythmias after cardiac surgery: a placebocontrolled, double blind, randomized trial. JAMA 1992, 268:2395-402.

15. Toraman F, Karabulut EH, Alhan C, Dagdelen S, Tarcan S: Magnesium infusion dramatically decreases the incidence of atrial fibrillation after coronary artery bypass grafting. Ann Thorac Surg 200I, 72: 1256-62.

16. Alghamdi AA, Al-Radi OO, Latter DA: Intravenous magnesium for prevention of atrial fibrillation after coronary artery bypass surgery: a systematic review and meta-analysis. J Card Surg 2005, 20:293-9.

17. Miller S, Crystal E, Garfinkle M, Lau C, Lashevsky I, Connolly SJ: Effects of magnesium on atrial fibrillation after cardiac surgery: a meta-analysis. Heart 2005, 91 1:618-623.

18. Blackstone E: Comparing apples and oranges. J Thorac Cardiovasc Surg 2002, I 23:8- 15 .

19. Parsons LS: Reducing bias in a propensity score match-pair sample using greedy matching techniques. In Proceedings of the Twenty-Sixth Annual SAS Users Group International Conference, Long Beach, CA Cary, NC: SAS Institute Inc; 2001.

20. Forlani S, De Paulis R, de Notaris S, et al.: Combination of sotalol and magnesium prevents atrial fibrillation after coronary artery bypass grafting. Ann Thorac Surg 2002, 74:720-6.
Publish with BioMed Central and every scientist can read your work free of charge

"BioMed Central will be the most significant development for disseminating the results of biomedical research in our lifetime. "

Sir Paul Nurse, Cancer Research UK

Your research papers will be:

- available free of charge to the entire biomedical community

- peer reviewed and published immediately upon acceptance

- cited in PubMed and archived on PubMed Central

- yours - you keep the copyright

Submit your manuscript here:

http://www.biomedcentral.com/info/publishing_adv.asp
BiolMedcentral 